\title{
Sobre la negación absoluta de la otredad en Francis Bacon
}

\author{
Diana Solano Villarreal \\ Escuela de Filosofía \\ Universidad Nacional, Costa Rica
}

\section{Resumen}

Este artículo versa sobre la negación del otro, siendo en principio los autóctonos americanos los otros y ahora, además, sus descendientes y los latinoamericanos en general. Se pretende analizar la negación de la otredad y su relación con el dominio en nuestros días, en las obras: El Avance del Aprendizaje, Preparación hacia una Historia Natural y Experimental, Valerius terminus: o de la Interpretación de la Naturaleza y Dignitate et Augmentis Scientiarum, de Bacon (1561-1626). Lo anterior desde la teoría del grupo Modernidad/Colonialidad, en los estudios de coloniales.

Palabras claves: otredad, dominio, negación, Francis Bacon

\begin{abstract}
This article deals with the negation of the other, being in principle the Native Americans the others and now also their descendants and Latin Americans in general. It is intended to analyse the denial of otherness and its relationship with the domain in our days, in the works: The Advancement of Learning, Preparation for a Natural and Experimental History, Valerius Terminus: or the Interpretation of Nature and Dignitate et Augmentis Scientiarum, of Bacon (1561-1626).

The aforementioned since the theory of the group modernity/coloniality, in the studies of colonial.
\end{abstract}

Keywords: otherness, domain, negation, Francis Bacon 


\section{Introducción}

Este artículo estudia la posición de Bacon respecto del Otro en los libros El Avance del Aprendizaje, Preparación hacia una Historia Natural y Experimental, Valerius terminus: o de la Interpretación de la Naturaleza y Dignitate et Augmentis Scientiarum. Aquí se explica cuáles son a mi entender las características de la negación del Otro de Francis Bacon.

La perspectiva teórica desde la cual realizaré la investigación propuesta es la que corresponde a la teoría del Grupo Modernidad/Colonialidad. Ahora bien, ¿cómo se relaciona la teoría del Grupo Modernidad/ Colonialidad con los escritos de Francis Bacon? Pienso que en los planteamientos epistemológicos baconianos se deja muy claro que el método que allí se expone no es para todos, y de ello podemos inferir que no todos están calificados para tener acceso a la verdad. El Dr. Bernal Herrera nos dice en su teoría de la Modernidad Bipolar (la cual se utilizará como apoyo para este trabajo), que en el polo metropolitano se dieron procesos liberadores basados en el conocimiento, los cuales no siempre fueron totales o completos, y en el polo colonial menos aún, pues no fueron pensados para ellos (Herrera, 2007: 20).

Francis Bacon es el más famoso y beligerante promotor de las ideas provenientes del Renacimiento, quien además creía firmemente que el conocimiento obtenido mediante el método correcto (su método inductivo) podía generar grandes beneficios al mundo. La naturaleza, ente misterioso y temido por el ser humano desde su aparición en el planeta, se podía estudiar, comprender y sistematizar realizando experimentos y extrayendo conclusiones a partir de las evidencias obtenidas, siguiendo el ya mencionado método inductivo. Bacon alegaba que, con un grupo de ingenios bien adiestrados, la investigación inductiva conduciría a la verdad, pero ¿Cuáles pueden ser estos ingenios? ¿Podemos partir de cualquier mente? $\mathrm{O}$ ¿Hay requisitos previos? ¿Cuáles podrían ser estos? ¿Serán estos requisitos más políticos que epistémicos?

\section{La otredad}

Antes de comenzar propiamente este apartado, es muy importante aclarar qué se entiende por otredad. La otredad es un concepto relativamente nuevo, no tan nuevo como los estudios decoloniales o poscoloniales pero ciertamente no es (la otredad) un concepto muy conocido fuera de los ya mencionados estudios. Así las cosas, la palabra otredad puede generar malos entendidos, los cuales es mejor evitar.

Según el diccionario en línea de la Real Academia de la Lengua, otredad significa algo tan simple como: Condición de ser otro. Definitivamente, una definición escueta y de hecho reduccionista, máxime si recordamos la compleja realidad para la que fue creada la palabra otredad.

La noción de otredad no es exclusiva de la filosofía. La sociología, la antropología y otras ciencias la utilizan con mucha soltura. La otredad se refiera al reconocimiento del Otro como un individuo diferente. $\mathrm{Al}$ distinguir la existencia del Otro, el individuo se reconoce a sí mismo. La otredad no supone, en sí misma, la discriminación del Otro. La 
discriminación o desacreditación del Otro son, por el contrario, justamente las acciones que se pretenden eliminar. Las disimilitudes que se perciben al estimar a un individuo cual sea como un Otro supone aceptación, apertura de mente y de espíritu.

La condición de otredad se constituye mediante diversos mecanismos psicológicos y sociales. El Otro entraña la presencia de algo extraño y por consiguiente no es pieza de la individualidad de cada uno. Empero, eso "raro" que encontramos en el Otro también puede vincular tanto la individualidad propia como la del sujeto a quién se considera Otro.

La negación de la otredad (como fenómeno) no es exclusiva de la Modernidad. Desde que las sociedades humanas se complejizaron, el ser humano ha negado al Otro. Primero con la mujer en cuanto diferente al hombre, y luego con el primer esclavo, a quienes se les reduciría a esta condición en tanto se les convertía en objetos por ser botín de guerra, o por la negativa a la libertad de vientre. En la Antigüedad occidental se negó a la mujer y al esclavo, en el Medioevo a la mujer, al esclavo y al siervo de la gleba, y en la Modernidad a la mujer y a todo aquel que no sea europeo o descendiente directo ${ }^{1}$ de europeos.

1 No siempre ha sido así. En el caso de las colonias españolas en América, la jerarquía social está basada en el color de piel y la ascendencia; los criollos, nombre que se les daba a los hijos de españoles nacidos en América, se encontraban en el segundo estamento de la pirámide, inmediatamente debajo de los peninsulares (españoles propiamente dichos, o bien nacidos en España en la Península Ibérica). A los criollos les estaban vedados los altos y medios puestos administrativos en el gobierno. De hecho se les permitían básicamente las labores comerciales, económicamente muy redituables, pero políticamente nulas.
Entre los principales poblemas de la perenne negación del Otro (es decir, no se procede al siguiente paso, al reconocimiento del Otro), se encuentra la imposibilidad de conocerlo y al no poder (y no querer) conocerlo, desaparece. Al desaparecer el Otro, es evidente que desaparecen también sus posibles derechos y oportunidades.

El asunto se convierte en un círculo vicioso toda vez que al negar al Otro este se desvanece, al ocurrir esto se desvanece también cualquier posibilidad de conocerle; al no poder conocerle se le niega por segunda vez y se le despoja entonces de cualquier empoderamiento y dignidad posibles. Aquí se hace evidente la teoría de las colonialidades del Grupo Modernidad/ Colonialidad, en la cual la Colonialidad del ser, del saber y del conocer están íntimamente interrelacionadas.

\section{Sin jerarquía epistémica, no hay posibilidad de jerarquía ontológica}

Si no hay jerarquía epistémica, no hay jerarquía ontológica. Es decir, lo que no puede ser conocido, no puede poseer existencia. Así de simple. Y aunque aceptáramos la máxima sin mayores cuestionamientos, surgen las preguntas: ¿Quién establece qué o quién puede ser conocido? ¿Qué o quién le otorga la potestad de decidir, de colocarse como sujeto ${ }^{2}$ ? En términos más académicos: ¿Quién habla? ¿Cuál es su lugar de enunciación?

En la Modernidad, la respuesta es la siguiente: el hombre adulto europeo. A la mujer europea se le permitirá un poco más

2 El sujeto, en la relación sujeto-objeto es la parte activa, en cambio el objeto es por definición pasivo. 
de dignidad, empero, no como la del hombre. El hombre europeo será quien hable, quien juzgue y dote o retire la jerarquía epistémica a los demás seres del planeta y su lugar de enunciación será Europa en principio; más adelante también Estados Unidos de América, Canadá y Australia.

Bacon, como representante de los intelectuales de su época y su continente, aparece ante nosotros como el típico ejemplo del autor que niega completamente a la otredad, no en tanto lo que dice sino, como expresa el Dr. Herrera, en lo que no dice (Herrera, 2007: 27) (aunque de hecho el filósofo inglés sí expresa su parecer al respecto de forma muy clara en un par de ocasiones). La ausencia de referencias epistémicas de otras culturas más allá de las europeas, la egipcia antigua (en tanto influencia para los helenos y hebreos) o la hebrea (en tanto esta última es la base de las religiones cristianas y creadora del Antiguo Testamento), nos dice mucho sobre la discriminación que el filósofo inglés aplicaba a las culturas no europeas:

...Pues así como el avance del saber depende en gran medida de las ordenanzas y régimen de las universidades dentro de los estados y reinos, así conocería aún mayor adelanto si hubiera más inteligencia entre las universidades de Europa de la que ahora hay. (Bacon: 1346) (El subrayado es nuestro)

En su obra El Avance del Saber, el joven Bacon realiza un recorrido desde los helenos hasta su tiempo intentando demostrar que el conocimiento que él considera verdadero no ha podido surgir por la falta de ciertos aspectos importantísimos como una detallada y objetiva historia del conocimiento.

Bacon no se detiene a considerar por ciencia, saber o conocimiento ninguna producción que no sea europea; deja de lado los fabulosos conocimientos que los árabes habían producido y acumulado durante siglos. No es posible que Francis Bacon, con todo su bajage de conocimientos, no tuviera siquiera una vaga noción de los saberes de esta riquísima cultura (la arábiga). Era bien sabido por los intelectuales de esa época y de algunos no tan instruidos, que fue por los sarracenos que buena parte de los textos helenos que con tanta soltura Bacon cita una y otra vez, llegaron a Europa. Bacon tenía que saberlo pues fue en Toledo a finales del siglo XII que los textos de Aristóteles (entre otros) se comenzaron a traducir al latín. ${ }^{3}$

La recalcitrante insistencia de Bacon por crear una auténtica historia de la ciencia en la mayoría de sus obras (lo cual puede llegar a ser abrumador), se refiere a una historia de los conocimientos más prácticos, aunque siempre guiados por la filosofía:

...Este conocimiento, siendo el final y término de la filosofía natural en la intención del hombre, no es, sin embargo, sino una porción de la filosofía natural si se lo considera a la totalidad

3 No es casualidad que fuera España el único lugar en Europa donde se pudieran traducir los textos helenos del árabe al latín, pues la cultura sarracena dominó en mayor o menor medida gran parte de la Península Ibérica por 760 años (Desde 732 d. C. con la Batalla de Poitiers, hasta 1492 con la caída de Granada). De allí que la lengua árabe fuera amplia y profundamente conocida. 
de la naturaleza. Y en general ha de seguirse esa norma, aceptar todas las particiones de los conocimientos más como líneas y venas que como secciones y separaciones, y mantener la continuídad e integralidad del conocimiento. Pues lo contrario ha hecho que algunas ciencias particulares se tornasen estériles, superficiales y erróneas, desde el momento en que han dejado de nutrirse de una fuente común. (Bacon: 2067- 2074).

El párrafo anterior nos deja muy claro que Bacon no pretendió que el conocimiento que se debía construir fuera divorciado de la filosofía; eso sería fatal para las ciencias las cuales no serían fuente de conocimiento verdaderamente tal, sin la madre de las ciencias. Por otra parte, no debemos perder de vista que todas estas recomendaciones se dirijen única y exclusivamente a Europa. La mente del Barón de Verulam no concebía otro lugar en el mundo, en el planeta Tierra, donde se pudiera construir conocimientos más que en el continente europeo.

Por otra parte, además del evidente eurocentrismo epistémico, la historia de la ciencia pretendida por Bacon presenta una de las más terribles características de la Modernidad: la etapización lineal de la Historia. El vizconde de Saint Albans no se toma el trabajo de justificar el porqué (talvez la asumió así inconcientemente) de una historia etapizada lineal; la da por supuesta. Explica por dónde se debe comenzar, por dónde se debe pasar y desde luego dónde terminar, pero la razón por la cual la historia de la ciencia es etapizada y lineal, no aparece por ninguna parte. Las razones por las que la ya mencionada historia es eurocentrada se obvian y tan solo aparecen algunas menciones peyorativas de las epistemes de los otros pueblos, las que terminan de afianzar el discurso racista que subyace en sus libros.

\section{La importancia de la historia en el establecimiento del verdadero conocimiento científico}

Puede ser que Benjamin Farrington tenga la razón al afirmar que Francis Bacon es el filósofo de la Ciencia Industrial ${ }^{4}$ en tanto la preocupación de Bacon por el conocimiento y el método adecuado para su avance, simplemente desborda en su obra intelectual. Empero, además existe otro aspecto muy importante en la preocupación por construir un verdadero conocimiento, su historia.

Y aunque la importancia que Bacon atribuye a la historia es de conocimiento general para muchas ciencias y disciplinas, en el marco del actual trabajo es sumamente importante pues uno de los instrumentos más poderosos que ha utilizado el eurocentrismo para consolidar y mantener el dominio de los pueblos conquistados (sus colonias) y posteriormente colonizados, ha sido manipular ${ }^{5} \mathrm{su}$ historia, en el mejor de los casos, y destruirla, en el peor. Un pueblo sin historia es un pueblo sin identidad.

4 Nótese que no utilizamos la traducción convencional del libro Francis Bacon: Filósofo de la Revolución Industrial, pues consideramos que la interpretación tradicional del mencionado título no corresponde realmente ni con el tema, ni con el espíritu verdadero de la obra de Farrington, toda vez que el concepto Revolución engloba aspectos socioculturales, políticos y económicos que si bien son abordados por Benjamin Farrington, el tema principal es la ciencia como el método de conocimiento que definió la era industrial.

5 Los mitos del progreso y la linealidad de la historia hacen en Bacon su magistral aparición. 
La construcción de la historia de la ciencia baconiana está repleta de mitos y prejuicios, ahora considerados grandes verdades para una muy buena parte de la población occidental y occidentalizada. Pensar en el avance en el tiempo como progreso en todas las áreas de influencia y que influencian al ser humano, es uno de esos mitos que han prejuiciado la historia de todo el mundo no europeo desde hace más de 500 años.

Cuando Bacon plantea la imperiosa necesidad de crear una historia del conocimiento (en y para Europa solamente, dejando de lado las influencias de otros pueblos), nos dice que se debe comenzar con los griegos, seguir con los romanos, luego los medievales $\mathrm{y}$, finalmente, con su tiempo (siglos XVI y XVII). Nos dice también no solo que la historia es lineal, sino que además debe serlo ${ }^{6}$. Debe serlo en tanto y en cuanto no se contempla otra forma de construir la Historia, si no es siguiendo un orden crono-lógico de los eventos.

Lo más interesante es que, como es harto conocido, la Historia en tanto comprensión del actuar de los pueblos en el tiempo y el espacio para entendernos mejor en el hoy, y con un poco de suerte no cometer los mismos errores, no se puede explicar como un simple recitar (o analizar ${ }^{7}$ ) los hechos históricos. La historia de los pueblos o la historia de todos los pueblos juntos (humanidad) no es una línea de relaciones

6 Esto último en obvio tono normativo moral, lo que lo vuelve sumamente peligroso.

7 Decimos analizar pues aunque se analicen los hechos históricos, depende de la visión de mundo del historiador y la perspectiva teórico- metodológica que lo guíe en su investigación, la historia se puede convertir igual en una explicación histórica viciada de linealismo. causales y mucho menos unicausales en la que aprendemos de nuestros errores y siempre estamos en constante mejora, avance, progreso.

Según Bacon, en su obra La Sabiduría de los Antiguos, los helenos ${ }^{8}$ (griegos antiguos) avanzaron mucho, tanto como sus instrumetos epistémicos les permitieron. Los romanos, mediante la conquista, se apropiaron de los conocimientos de los helenos y los superaron. Más adelante, los medievales descubrieron algunas cuestiones interesantes y, finalmente, la Europa Moderna hace los más grandes descubrimientos e inventos hasta la fecha. No obstante, la historia no funciona así para ninguna cultura del planeta.

La Historia (así con mayúscula) ha sido objeto de la especulación filosófica, tal cual lo han sido todos los tipos de conocimientos (aunque fuera para desacreditarlos como tales). Se ha intentado encontrarle un sentido, un fin tanto en el sentido de un final de la Historia (el día en que ya no se dé más la Historia ${ }^{9}$ ) o en tanto Telos, donde se alcanzarán las más ambicionadas perfecciones (la dictadura del proletariado, por ejemplo). Sea la linealidad de la Modernidad, el avasallante poder del espíritu absoluto de Hegel

8 Nótese que no decimos griegos, ni griegos antiguos, toda vez que los habitantes del territorio (antes más extenso que ahora) de lo que hoy conocemos como Grecia, nunca se hubieran identificado como griegos. No lo hubieran hecho porque para ellos el territorio que ocuparon las más de mil Polis (en el momento de auge) en la península del Peloponeso, nombraban este trozo de tierra Helade, no Grecia. En ese sentido, el gentilicio para los habitantes de la Helade será helenos.

9 Tal cosa parece imposible a nuestros ojos. Para que la historia desaparezca debe desaparecer primero el ser humano. Mientras exista el ser humano, existirá la historia, no importa si no se registra de forma escrita. 
o el materialismo histórico, lo cierto es que la Historia no se acomoda completamente a las categorías en que, muy a conveniencia de algunos, se le ha tratado de encajonar.

Talvez tenga razón Agnes Heller cuando al hablarnos de la contingencia en la Historia nos dice que si es el caso y la Historia no tiene un fin, un Telos, eso no nos libera de responsabilidad alguna, al contrario, nos obliga en todos los niveles a responsabilizarnos del curso que esta tome, pues ese será el curso que nosotros le demos. (Heller, 1999, 289)

El caso es que ni siquiera la historia de la tecnología es lineal y con avance permanente; varios descubrimientos arqueológicos en el mismo Viejo Mundo (sin mencionar las culturas autóctonas americanas) han probado que la Historia es un constante ir y venir, apender, olvidar y volver a aprender en todos los aspectos de la vida de las sociedades. Ejemplo de estos descubrimientos arqueológicos son La Máquina de Vapor, en la antigua Biblioteca de Alejandría ${ }^{10}$ y El Mecanismo de Antikythera, en el Egeo ${ }^{11}$.

Bacon concebía la Historia como lineal, en la cual el avance en el tiempo supone progreso y aunque el filósofo inglés no dice gran cosa respecto a la historia de los pueblos, podemos inferir de este silencio lo que podría significar para los pueblos no europeos del mundo. La

10 Creada con el nombre de aelópila por Herón de Alejandría durante el siglo primero de nuestra era.

11 Hallado en el año 1900 en Grecia, en el Mar Egeo, frente a la isla de Antikythera, está datada en el año 80 d. C. Se encuentra expuesto en el Museo Arqueológico Nacional de Atenas. siguiente cita del Avance del Saber nos puede dar una idea:

... aún así antes se creerá que Prometeo primero golpeó los pedernales, y se quedó asombrado ante la chispa, que no que cuando primero los golpeó esperaba la chispa; de donde vemos que Prometeo de las Indias Occidentales no tenía inteligencia con el europeo, por la escasez en ellas del pedernal, que fue lo que suministró la primera ocasión. (2402)

El parrafo anterior deja claro y sin lugar a dudas el hecho que Francis Bacon, Varón de Verulam, efectivamente consideraba a los autóctonos americanos menos inteligentes que a los europeos “...donde vemos que el Prometeo de las Indias Occidentales no tenía inteligencia con el europeo..." por no contar con la piedra pedernal ${ }^{12}$ y por ello menos capaces de crear un conocimiento válido, pues hay que recordar que en la Modernidad no todo conocimiento es válido, es más, la palabra conocimiento será reservada para el conocimiento científico, y las élites intelectuales conformadas por hombres adultos europeos o eurodescendientes directos (estadounidenses, australianos, sudafricanos blancos) velarán por él durante más de 350 años. De esta manera, es evidente que pensar en una historia de la ciencia fuera de Europa, y específicamente en lo que

12 De hecho, sí hay bastante pedernal en América, sino que también y muy irónicamente para el pensamiento baconiano, además tenemos la muy apreciada oxidiana que hoy es utilizada para muchísimas cosas, entre ellas en las cirugías oculares. 
más adelante se conocerá como América ${ }^{13}$, no tendría mayor sentido.

En palabras simples, aunque para Bacon escribir una historia de la ciencia era más que importante, era fundamental pues sabía que, al igual que en las culturas, en la construcción de los conocimientos se debe saber cuáles son los principios últimos en que se dan sus cimientos para determinar lo concerniente a su desarrollo (del conocimiento).

Más arriba dijimos que en la Modernidad se aplica una fórmula muy sencilla, pero con consecuencias terribles: la jerarquía epistémica determina la jeraquía ontólogica. Los autóctonos americanos no se consideraban tan inteligentes como los europeos. Lo anterior, además de indignante, es muy serio, pues al restar inteligencia a los autóctonos americanos, también les restan autonomía y la capacidad de autodeterminación, por lo que se les condena a la minoría de edad eterna y con ella a la eterna necesidad de un tutelaje. Este tutelaje que deberá ser ejercido por un individuo apto, es decir reponsable e inteligente, solo puede ser un varón adulto europeo.

Además de todo lo anterior, ser menos inteligente implicaba que no podíamos conocer como ellos, por eso pasaríamos de la posibilidad de ser sujetos en la ecuación sujeto-objeto (tan problemática para las

13 Lo más irónico del caso de América es que fueron los mismos europeos quienes (el tristemente célebre caso de los aztecas es especialmente icónico) destruyeron los registros materiales de las culturas que aquí habitaban. Los cronistas españoles nos cuentan que por orden de Hernán Cortez, los textos del Templo Mayor de Tenochitlán ardieron. Tal era la cantidad de manuscritos que, según registros, la quema se prolongó durante dos largas semanas. disciplinas sociales ${ }^{14}$ ) y anclarnos en la posición de objetos. Los otros, nosotros. Los no europeos no somos reconocidos como iguales. Somos simplemente negados.

Negados como sujetos en el estudio, objetos para ser analizados desde la objetividad de la ciencia moderna. Hemos sido tratados como cosas sin mayor importancia más allá de la posibilidad de utlilizarnos para algo. Un ejemplo muy reciente, de la segunda mitad del siglo XX, fue el de la muy celebrada vacuna contra la poliomielitis que se aplicó masivamente en Kenia, varios años antes de que se aplicara a la población estadounidense. Primero se prueba, si no funciona bien, se vuelve para buscar el error y se vuelve a probar. Al final, la prueba por ser tal se aplica en algo que no importe tanto o nada estropear. La rotunda negación del otro.

\section{La moralización de la razón y la inteligencia}

Existe una situación a la cual posiblemente no se le dé mayor importancia (justamente por nuestra mentalidad moderna) y es que ya para el siglo XVI comenzaba el proceso de unir la inteligencia y la razón (sea lo que eso sea) con el bien. Para la mentalidad occidental y occidentalizada, la razón y la inteligencia se ha convertido en sinónimo de bien y este es un aspecto al que hay que ponerle atención, pues sus

14 Decimos disciplinas y no ciencias pues no cuentan con la posibilidad de la experimentación controlada, requisito indispensable para ser ciencia moderna. No obstante, y esto es crítico, no significa que no sea conocimiento válido e importante, o que no se encuentre a la altura del saber generado por las llamadas ciencias exactas o duras, toda vez que no compartimos el muy conocido dogma moderno, el cual reza: el único conocimiento (verdadero) es el científico. 
implicaciones son peligrosamente profundas. Para explicarnos mejor, acudiremos a un ejemplo que de hecho se dio, se da y posiblemente se siga dando y es la unión del bien con la belleza.

Para los helenos el bien y la belleza eran equivalentes. Lo bueno es bello y lo bello es bueno, entonces ( $\mathrm{y}$ aunque suene tonto y redundante) lo malo es feo y lo feo es malo. La primera parte de la ecuación no supone mayor problema, es la segunda parte la que parece muy nebulosa.

El hecho de que algo (lo que sea) sea feo, no quiere decir que sea malo o que carezca de significado e importancia. Por ejemplo, el dolor físico o emocional. El dolor no es una sensación placentera; dependiendo de su intensidad el individuo se puede sentir en la antesala del infierno dantesco. Empero, aunque feo, el dolor no siempre es malo. En muchas ocasiones es bueno y necesario. Es necesario (en el caso del dolor físico) cuando nos alerta de que se están lacerando los tejidos del cuerpo y que de seguir así se podría povocar un daño irreparable en nervios u órganos vitales, por lo que hay que detenerse y remediar la situación que produce el malestar.

En el caso del dolor emocional, por ejemplo la terrible sensación de la angustia que nos agita y desespera, no aparece solo para martirizarnos, aparece para alertarnos de que algo no anda bien y que debemos atendernos. Por lo anterior, los psicólogos insisten (contrario a lo que nos quiere vender la industria farmaceutica) en que no logramos nada bueno acallando los gritos desaforados de la angustia con ansiolíticos, sean naturales o sintéticos.
El llamado de atención de nuestra psique en forma de angustia pretende alertarnos sobre algo que se debe atender urgentemente y apagando la alarma de la angustia sin tomar las medidas pertinentes en nada nos ayuda, pues la angustia volverá con su grito una y otra vez, más alto y desesperado. Empero, más allá de las de por sí importantes cuestiones psíquicas y biológicas, en lo fenotípico el ser calificado como feo significará entonces (y esto con mucho cuidado) ser malo ${ }^{15}$.

El largo ejemplo anterior tiene por objetivo introducir adecuadamente el subtema de este apartado, la moralización de la inteligencia y la racionalidad. En nuestros días, no existe una relación de sinonimia entre razón y bien como la ya mencionada relación belleza-bien de los helenos, pero sí existe una fuerte correspondencia entre razón y bien.

Desde luego no estamos diciendo que Francis Bacon introdujo o siquiera insinuó la relación razón-bien que pretendemos probar. No obstante, la fuerte importancia que le da a la inteligencia el filósofo inglés, tuvo su papel en esta situación. No creemos que de forma conciente ni mal intencionada, pero la situación en la que desembocó es la que tenemos y hemos tenido desde hace siglos.

Es verdad que muchos autores anteriores al Visconde de Saint Alban, tales como Juan Luís Vives, Desiderio Erasmo y Maquiavelo, entre otros, no solo mencionaron sino que de hecho tomaron un espacio

15 No ahondaremos en esta interesante problemática por razones de espacio y porque excede los modestos propósitos de este trabajo. 
importante en sus repectivas obras para el examen de la cuestión de los ingenios o inteligencias. Empero, ninguno de los anteriores $^{16}$ ha influido tan determinante $y$ profundamente en el pensamiento occidental como lo hizo el padre del Empirismo.

Para Bacon, los autóctonos americanos o salvajes (Bacon: 2274) (palabra despectiva y sinónimo por excelencia para el otro) no son tan inteligentes como los europeos (ver cita textual) y eso los vuelve menos en muchos más aspectos, como explicamos anteriormente.

Ahora bien, desde una perspectiva científica actual, el ser más o menos inteligente $^{17}$ no implica que el individuo sea mejor o peor persona en ningún aspecto, pero para la colectividad en el diario vivir, ser o no inteligente significa desde no ser apto para un trabajo simple, hasta ser una mala persona. Que una persona tenga más o menos razón ${ }^{18}$ es la medida para determinar el grado de verdad en el que se encuentra en determinada situación. Estar en la razón es estar en la verdad y estar con la verdad es estar con el bien. La inteligencia es la llave que nos abre la puerta de la razón. Cuanta más inteligencia

16 Ni Juan Luís Vives ni Desiderio Erasmo expresaron en sus trabajos ningún tipo de insinuación respecto a superioridad de los europeos en cuanto a inteligencia.

17 El asunto de la inteligencia (capacidad de resolver problemas) ha sido largamente estudiado, empero no fue hasta la publicación del texto La teoría de las inteligencias múltiples (1983) de Howard Gardner, cuando comenzamos a darnos cuenta en Occidente de que la inteligencia lógico- matemática no es la única ni la más importante de las inteligencias.

18 Más adelante en 1629, Descartes nos dirá en la obra cumbre y fundante de la modernidad según las teorías tradicionales, El Discurso del Método, que todo ser humano tiene la misma capacidad de razonar; el meollo del asunto está en cómo se utiliza esta capacidad. poseamos, más podremos accesar a la $l u z^{19}$ de razón (consigna de la Ilustración).

Entonces, si la razón es buena pero solo llegamos a ella por vía de la inteligencia, en tanto más o menos inteligentes seamos, más o menos buenos seremos. Muchos de los habitantes de los países europeos siguen considerando a los autóctonos americanos, a los africanos, a los afrodescencientes y a los latinoamericanos en general, como no tan inteligentes como ellos, lo que significa que no somos tan buenos como ellos y por eso no merecemos las mismas consideraciones epistémicas ni morales.

\section{Conclusiones}

Ser el Otro nunca ha sido fácil desde que la humanidad es humanidad (y posiblemete desde antes). El ser humano tiende a segregar al que es diferente, algunas veces con motivos correctos (comportamientos y conductas que podrían lacerar la integridad física y emocional de los individuos que conforman la colectividad), a veces sin ellos.

Empero, ser diferente, ser el Otro en sí, no es una amenaza en sí misma. En esta era que nos ha tocado vivir llamada Modernidad, el color de la piel junto con el lugar donde se nació, han definido a la Otredad y se ha justificado con el pensamiento de algunos autores como Francis Bacon.

Bacon fue un eurocéntrico quien consideraba al resto de la humanidad, la Otredad, epistémicamente incapacitada, falta de la inteligencia necesaria para la producción de

19 La luz (bien) de la razón que ilumina las tinieblas (mal) de la ignorancia y la superstición. 
conocimiento válido, meros objetos a los que no había que molestarse demasiado en conocer, restándoles así la jerarquía ontológica necesaria para considerarse visibles.

\section{Bibliografía}

Bacon, F. (2009). Novum Organon. Madrid: Trotta.

Cajigas-rotundo, J. (2007). "La biocolonialidad del poder. Amazonía, biodiversidad y ecocapitalismo". En Santiago Castro-Gómez y Ramón Grosfoguel (comps.). El giro decolonial. Reflexiones para una diversidad epistémica más allá del capitalismo global. Bogotá: Universidad Javeriana-Instituto Pensar, Universidad Central-IESCO, Siglo del Hombre Editores.

Castro-Gómez, S. (1996). Crítica de la razón latinoamericana. Barcelona: Puvill Libros.

Castro-Gómez, S. (2005). La hybris del punto cero. Ciencia, raza e Ilustración en la Nueva Granada 17501816. Bogotá: Universidad Javeriana-Instituto Pensar.

Castro-Gómez, S. (2005). "Ciencias sociales, violencia epistémica y el problema de la 'invención del otro'. En Edgardo Lander (comp.). La colonialidad del saber: eurocentrismo y ciencias sociales. Perspectivas Latinoamericanas. Buenos Aires: Clacso.

Castro-Gómez, S. (ed.). (2000) La reestructuración de las ciencias sociales en América Latina. Bogotá: Instituto Pensar.

Castro-Gómez, S., Guardiola-Rivera, O. y Millán de Benavides, C. (eds.). (1999). Pensar (en) los intersticios.
Teoría y práctica de la crítica poscolonial. Bogotá: Instituto Pensar.

De las Casas, B. En: http:www.ordiecole. com/las_casas_destruccion.pdf

Descartes, R. (1986). Discurso del método. Madrid: Alianza Editorial.

Dussel, E. (1983). Introducción a la filosofía de la liberación. Bogotá: Editorial Nueva América.

Dussel, E. (1992). "Del descubrimiento al desencubrimiento". En Nuestra América frente al V centenario. Bogotá: Editorial El Búho.

Dussel, E. (2005). "Europa, modernidad y eurocentrismo". En Edgardo Lander (comp.). La colonialidad del saber: eurocentrismo y ciencias sociales. Perspectivas Latinoamericanas. Buenos Aires: Clacso.

Dussel, E. (1992). 1492. El encubrimiento del otro. Hacia el origen del mito de la modernidad. Madrid: Nueva Utopía.

Dussel, E. (1998). Ética de la liberación en la edad de la globalización y de la exclusión. Madrid: Trotta.

Dussel, E. (2007). Política de la liberación. Historia mundial y crítica. Madrid: Trotta.

Escobar, A. (2005). Más allá del Tercer Mundo: Globalización y Diferencia. Bogotá: ICANH.

Escobar,A. "Mundos y conocimientos de otro modo". En: http://www.decoloniality. net/files/escobar-tabula-rasa.pdf

Fanon, F. (2003). Los condenados de la tierra. Prefacio de Jean-Paul Sartre. Epílogo de Gérard Chaliand. México: Fondo de Cultura Económica.

Farrington, B. (2000). Francis Bacon, Filósofo de la Revolución Industrial. Madrid: ENDYMION. 
Foucault, M. (2000). La verdad y las formas jurídicas. Barcelona: Gedisa.

Foucault, M. (1987). Vigilar y castigar. Madrid: Alianza Editorial.

Galilei, G. (1891). El ensayador. Buenos Aires: Aguilar.

Galeano, E. (1992). Ser como ellos y otros artículos. Buenos Aires: Siglo XIX.

Garcés, F. (2007). "Las políticas del conocimiento y la colonialidad lingüística y epistémica". En Santiago Castro-Gómez y Ramón Grosfoguel (comps.). El giro decolonial. Reflexiones para una diversidad epistémica más allá del capitalismo global. Bogotá: Universidad Javeriana-Instituto Pensar, Universidad Central-IESCO, Siglo del Hombre Editores.

Grosfoguel, R. (2007). “Decolonizando los universalismos occidentales: el pluriversalismo transmoderno decolonial desde Aimé Césaire hasta los Zapatistas". En Santiago Castro-Gómez y Ramón Grosfoguel (comps.). El giro decolonial. Reflexiones para una diversidad epistémica más allá del capitalismo global. Bogotá: Universidad Javeriana-Instituto Pensar, Universidad Central-IESCO, Siglo del Hombre Editores.

Habermas, J. (1986). La modernidad un proyecto incompleto. En VVAA, $L a$ posmodernidad. Barcelona: Kairós.

Herrera, B. (2007). Las dos caras de la moneda: modernidad colonial $y$ metropolitana. En: Pasos. San José, DEI.

Hernández, A. Descartes: El discurso del método. Googlebooks.

Heller, A. (1999). Una filosofía de la historia en fragmentos. Barcelona: Gedisa.
Husserl, E. (1991). La crisis de las ciencias europeas y la fenomenología trascendental. Barcelona: Crítica.

Kamen, H. (1999). La inquisición española. Una revisión histórica. Barcelona: Crítica.

Lander, E. (ed.). (2000). La colonialidad del saber. Eurocentrismo y ciencias sociales. Perspectivas latinoamericanas. Buenos Aires: CLACSO.

Libro de las puertas. En: http://www.egiptología.org/textos/puertas/

Manzo, S. (2008) Los usos políticos del cuerpo: los dos cuerpos del Rey en la filosofía de Francis Bacon. En: http://www.scielo.br/pdf/kr/ v49n117/a1149117.pdf

Mignolo, W. (ed.). (2001). Capitalismo y geopolítica del conocimiento. El eurocentrismo y la filosofía de la liberación en el debate internacional contemporáneo. Buenos Aires: Ediciones del Signo.

Maldonado-Torres, N. (2007). "Sobre la colonialidad del ser: contribuciones al desarrollo de un concepto". En Santiago Castro-Gómez y Ramón Grosfoguel (comps.). El giro decolonial. Reflexiones para una diversidad epistémica más allá del capitalismo global. Bogotá: Universidad Javeriana-Instituto Pensar, Universidad Central-IESCO, Siglo del Hombre Editores.

Mignolo, D. W. (2002). "Colonialidad global, capitalismo y hegemonía epistémica”. En Santiago CastroGómez, Freya Schiwy y Catherine Walsh, (comps.). Indisciplinar las ciencias sociales. Geopolítica del conocimiento y colonialidad del poder. Perspectivas de lo andino. 
Mignolo, D. W. (2002). Historias locales/ diseños globales. Colonialidad, conocimientos subalternos y pensamiento fronterizo. (Prefacio). México: Akal Ediciones.

Mignolo, D. W. (2005). "La colonialidad a lo largo y a lo ancho: el hemisferio occidental en el horizonte colonial de la modernidad". En Edgardo Lander (comp.). La colonialidad del saber: eurocentrismo y ciencias sociales. Perspectivas Latinoamericanas. Buenos Aires: Clacso.

Mignolo, D. W. (2007). "El pensamiento decolonial: desprendimiento y apertura”. En Santiago Castro-Gómez y Ramón Grosfoguel (comps.). El giro decolonial. Reflexiones para una diversidad epistémica más allá del capitalismo global. Bogotá: Universidad Javeriana-Instituto Pensar, Universidad Central-IESCO, Siglo del Hombre Editores.

Quijano, A. (2007). "Colonialidad del poder y clasificación social”. En Santiago Castro-Gómez y Ramón Grosfoguel (comps.). El giro decolonial. Reflexiones para una diversidad epistémica más allá del capitalismo global. Bogotá: Universidad Javeriana-Instituto Pensar, Universidad Central-IESCO, Siglo del Hombre Editores.

Negri, A. (2008). Descartes Político. Madrid: Ediciones Akal.

Negri, A. (2008) Descartes político. En: http://books.gloogle.es/books?i $\mathrm{d}=\mathrm{af} 82 \mathrm{t} 651 \mathrm{VSqUC} \&$ printsec $=\mathrm{fr}$ ontcover\&dq=intitle: descartes+ intitle:político/inauthor:antonio/ inauthor:negri
O’Gorman, E. (2002). La invención de América. México: Fondo de Cultura Económica.

Pachón, D. (2006). Filosofía vitalista y economía solidaria. Bogotá: Produmedios.

Peltonen, M. (ed.). (1996). "Bacon's political philosophy". En: The Cambridge Companion to Francis Bacon. http://books.google. com/books/about/The_Cambridge_Companion_to_Bacon.htm1?id=aXyc_VCh4y0C\&redir_esc $=y$

Quijano, A. (2005). "Colonialidad del poder, eurocentrismo y América Latina”. En Edgardo Lander (comp.). La colonialidad del saber: eurocentrismo y ciencias sociales. Perspectivas Latinoamericanas. Buenos Aires: Clacso.

Quijano, A. (1998) “Colonialidad, Poder, Cultura y Conocimiento en América Latina". En Anuario Mariateguiano, vol. IX, No. 9, pp.113-122. Lima.

Quijano, A. (1992). "Colonialidad y Modernidad/Racionalidad". En Heraclio Bonilla (comp.). Los Conquistados. 1492 y la población indígena de las Américas. Bogotá: FLACSOTercer Mundo.

Quijano, A. (1989). Modernidad, Identidad y Utopía en América Latina. Quito: Ediciones El Conejo.

Restrepo,E. (2007). “Antropología y colonialidad”. En Santiago Castro-Gómez y Ramón Grosfoguel (comps.). El giro decolonial. Reflexiones para una diversidad epistémica más allá del capitalismo global. Bogotá: Universidad Javeriana-Instituto Pensar, Universidad Central-IESCO, Siglo del Hombre Editores. 
Sepúlveda, G. (1951). Demócrates segundo o de las justas causas de la guerra contra los indios. Madrid: Consejo Superior de Investigaciones Científicas. Instituto Francisco de Vitoria. En: www.books.google. com/Juan_Ginés_de_Sepúlveda

Sepúlveda, G. (1987). Tratado sobre las justas causas de la guerra contra los indios. México: Fondo de Cultura Económica.

Todorov, T. (1987). La Conquista de América. El problema del otro. México: Siglo XXI.
Walsh, C. (2007). "Interculturalidad y colonialidad del poder. Un pensamiento y posicionamiento 'otro' desde la diferencia colonial”. En Santiago Castro-Gómez y Ramón Grosfoguel (comps.). El giro decolonial. Reflexiones para una diversidad epistémica más allá del capitalismo global. Bogotá: Universidad Javeriana-Instituto Pensar, Universidad CentralIESCO, Siglo del Hombre Editores.

Weber, M. (1997). La ética protestante y el espíritu del capitalismo. Barcelona: Editorial Península. 